\title{
Impacto Econômico da Universidade de Brasília no Distrito Federal e Brasil
}

\author{
Moisés Diniz Vassallo $^{1}$ (D) | Milene Takasago 2 (D) | Maria Carolina Marques ${ }^{3}$ (D) \\ ${ }^{1}$ Professor adjunto no Instituto de Engenharia de Produção e Gestão da Universidade Federal de Itajubá. E-mail: \\ moisesvassallo@gmail.com \\ 2 Professora associada do Departamento de Economia da Universidade de Brasília. E-mail: milene@unb.br \\ ${ }^{3}$ Doutoranda em Economia Aplicada na Universidade de Brasília. E-mail: carolmcmarques@gmail.com
}

\section{RESUMO}

Neste artigo, buscou-se avaliar os efeitos que a Universidade de Brasília - UnB exerce na economia do Distrito Federal - DF, a partir dos impactos calculados com uso de modelo de Insumo-Produto inter-regional. Quando consideramos o valor adicionado bruto, a UnB é responsável por cerca de R\$ 2,5 bilhões de reais, o equivalente a 1\% do PIB do DF. Adicionalmente, a UnB gera cerca de 45 mil empregos no DF e é responsável pela arrecadação de R\$ 277 milhões em tributos. Esses indicadores foram apresentados em termos de impactos diretos somados aos indiretos e induzidos.

\section{PALAVRAS-CHAVE}

Matriz de insumo-produto, Multiplicadores de impacto, Universidade de Brasília

\section{Economic Impact of the University of Brasilia in the Federal District and Brazil}

\begin{abstract}
In this article, we evaluate the effects that the University of Brasilia (UnB) has on the economy of the Federal District (DF), based on the impacts calculated using an interregional input-output model. When we consider the added value, Unb is responsible for approximately 2.5 billion reals, equivalent to $1 \%$ of the Gross Domestic Product (GDP) of the Federal District. In addition, UnB generates about 45 thousand jobs in the DF, and is also responsible for collecting 277 million reals in taxes. These indicators were presented in terms of direct impacts added to indirect and induced.
\end{abstract}

\section{KEYWORDS}

Input-output matrix, Impact multipliers, Brasilia of the University

\author{
CLASSIFICAÇÃO JEL \\ R15, R13, R58
}




\section{Introdução}

No final dos anos 90, as políticas públicas relacionadas à educação superior foram direcionadas para a expansão das instituições de ensino superior, com propostas para ampliar a oferta desse segmento no país. A justificativa para tais políticas está relacionada à baixa participação de jovens, com idade entre 18 e 24 anos, no ensino superior, principalmente quando comparada ao observado em diversos países, desenvolvidos ou em desenvolvimento (Vinhais, 2013).

Dentre os principais efeitos observados pela expansão das instituições de ensino superior, pode-se citar o aumento anual médio de 7,8\% dos gastos públicos (em termos reais) para as universidades federais brasileiras e a ampliação do quadro de docentes, de 48.868, em 2002, para 74.049, em 2010 (Niquito et al., 2018).

Com a expansão das universidades, torna-se relevante avaliar os impactos econômicos das instituições de ensino superior para o desenvolvimento das regiões em que estão localizadas e verificar seus desdobramentos para além da região, ou seja, no resto do Brasil, Kureski e Rolim (2011). Neste sentido, este estudo busca avaliar os impactos econômicos, associados à movimentação econômica e cadeia de valor da Universidade de Brasília-UnB no Distrito Federal e no restante da economia brasileira.

A UnB teve sua criação autorizada em 15 de dezembro de 1961, pelo então presidente da República João Goulart. Atualmente, a UnB possui quatro campi, sendo esses em Brasília (Campus Darcy Ribeiro), em Planaltina (Faculdade UnB Planaltina), no Gama (Faculdade UnB Gama) e em Ceilândia (Faculdade UnB Ceilândia).

Entre as 67 universidades federais do Brasil mantidas pela União, por meio de recursos do Ministério da Educação, a UnB é a universidade com o quarto maior orçamento. Desde a sua criação, a UnB tem um papel extremamente importante, tanto nacionalmente quanto regionalmente, no que diz respeito à excelência do ensino e da pesquisa. São mais de 70 cursos presenciais. Também podemos destacar sua importância regional, citando o Índice Geral de Cursos, calculado pelo Instituto Nacional de Estudos e Pesquisas Educacionais Anísio Teixeira (Inep), autarquia do Ministério da Educação, que classificou a UnB como a melhor universidade da região Centro-Oeste.

Em termos metodológicos, destaca-se para este estudo, a elaboração de uma matriz inter-regional de insumo-produto para o DF e resto do Brasil em colaboração o professor Joaquim José Martins Guilhoto. Com o uso dessa matriz e de pesquisas diretas e indiretas, buscou-se avaliar os impactos econômicos diretos, indiretos e induzidos que a UnB produz no DF e no Brasil. Esses impactos foram mensurados em termos de valor bruto da produção (VBP), valor adicionado bruto (VAB), geração de empregos e arrecadação de impostos indiretos líquidos. 


\section{Importância das Instituições Federais de Ensino Superior (IFES) na economia de uma região}

Além das inúmeras funções sociais das universidades, é relevante conhecer o impacto econômico que a presença de uma universidade exerce sobre a economia local.

A natureza da participação e o envolvimento do governo federal na manutenção da Universidade de Brasília caracterizam este estudo como uma avaliação de impacto de política pública. Neste sentido, procura-se avaliar qual o impacto econômico para esse envolvimento e qual o retorno em termos de Valor Bruto da Produção, Valor Adicionado Bruto e geração de ocupações, no Distrito Federal e para sua população, que justifica a alocação de recursos públicos para seu financiamento, além daqueles associados à promoção da educação pública de excelência.

A avaliação econômico-financeira da manutenção de uma universidade comporta diferentes tipos de abordagens, dependendo da ótica dos objetivos e interesses de cada uma das partes envolvidas na sua viabilização e manutenção. São agentes de interesse os estudantes, os servidores e os professores e os setores produtivos, como a indústria e o comércio, que recebem mão de obra mais capacitada e que têm na universidade uma fonte de demanda por bens e serviços de consumo e de investimento. Na maioria dessas abordagens, prevalece o enfoque da chamada análise privada que, em consonância com a lógica de empreendimentos que visam primordialmente à obtenção do lucro, busca identificar e analisar apenas os fenômenos e os impactos que implicam em pagamentos e recebimentos pecuniários para a parte interessada sob análise. Tratam-se, portanto, de análises em que os custos e benefícios da universidade são, em geral, bem definidos e quantificáveis, possibilitando obter cifras conclusivas do resultado líquido dessa participação.

A análise do impacto econômico para o desenvolvimento de uma região, devido à presença de uma universidade, sob o ponto de vista da participação do governo federal como ente financiador da instituição, certamente não se enquadra naquele enfoque restrito da análise privada. Isso ocorre porque não se pode considerar que os objetivos perseguidos pelo governo federal se resumem ao retorno financeiro, na forma de acréscimo de receita de impostos, propiciada pela universidade.

A exemplo das inúmeras experiências observadas no mundo, de participação de governos locais e nacionais de países de variados niveis de desenvolvimento, na promoção da educação, os objetivos desse tipo de atuação governamental estão associados com a promoção do desenvolvimento econômico e social da região ou mesmo do país, levando em conta não só seus impactos econômicos e sociais imediatos, mas também os impactos de longo prazo e suas externalidades em outras áreas, nas quais os resultados não são medidos em termos financeiros, como aumento da expectativa de vida, redução da criminalidade, ganhos com saúde e qualidade de vida.

Frente a essa multiplicidade de objetivos e de tipos de impactos que necessitam 
ser considerados na avaliação da participação do governo federal na manutenção das universidades federais, fica então patente que é necessário enfocar essa análise como sendo propriamente uma decisão de política pública.

Avaliar então a atuação do governo federal na manutenção das universidades públicas, sob o enfoque da análise de uma política pública, gera como implicação imediata o significativo aumento do grau de complexidade dessa análise, quando comparada com aquela de natureza privada.

Esse maior grau de complexidade é decorrente de problemas de duas naturezas. O primeiro deles está associado com a limitada capacidade de mensuração dos efeitos e impactos da política pública, isso porque usualmente é necessário avaliar benefícios e custos que envolvem dificuldades de especificação e de mensuração. Um exemplo de efeitos de difícil mensuração são os impactos não tangiveis, ou seja, para os quais não existem valorações de mercado (por exemplo melhoria da qualidade e expectativa de vida, nível de cultura, de saúde ou de lazer dos indivíduos). Outro exemplo são efeitos que ocorrem ao longo de um período relativamente grande e indeterminado de tempo, por exemplo o incremento do bem-estar e da saúde da população, ou simplesmente o efeito da divulgação de uma localidade nas mídias internacionais e sua relevância mundial em termos de atração de investimentos e pesquisadores, gerando assim um ciclo virtuoso em torno da universidade.

O segundo tipo de problema que torna complexa a análise das políticas públicas é de natureza conceitual e filosófica. É preciso considerar que os vários tipos de efeitos benéficos e prejudiciais de uma política pública incidem sobre diferentes subgrupos de indivíduos, ou seja, existe um aspecto de distribuição pessoal dos benefícios e ônus da política. Dessa forma, não se pode adotar como critério de avaliação de uma determinada política a simples comparação do valor total dos benefícios com o dos custos, nem avaliar que uma política é superior ou mais desejada do que outra, pelo simples fato de o seu valor total de benefícios, líquido dos custos, ser superior ao de outra.

Nesse procedimento de se computar o valor total dos benefícios e dos custos de uma política está implícito o pressuposto de que faz sentido agregar e, portanto, comparar valores de benefícios de diferentes indivíduos e contrapô-los aos valores de custos de outros indivíduos. Ou seja, adota-se implicitamente um sistema de juízo de valor que estabelece que $\mathrm{R} \$ 1,00$ de benefício ou de custo tem o mesmo impacto sobre o bem-estar de qualquer indivíduo, independentemente da sua posição socioeconômica relativa.

Nesse sentido, prevalece que a questão da avaliação de qualquer política pública, bem como da adequação da alocação dos recursos entre diferentes políticas não é uma questão técnica, mas política, no sentido de que é necessário adotar algum tipo de mecanismo de escolha e decisão socialmente aceita. O sistema de decisão de governos eleitos democraticamente pela população representa uma criação e um desenvolvi- 
mento da humanidade para essa questão.

Apesar disso, o caráter político da decisão de implementação das políticas públicas não significa que não sejam relevantes as análises econômicas em relação a elas. Ao contrário, dada a complexidade do processo de elaboração e acompanhamento do plano de alocação dos recursos entre um conjunto grande de políticas públicas, cada uma delas com as suas especificidades e multiplicidade de objetivos e de efeitos e impactos, entende-se que essas análises se constituem um instrumento útil para tornar mais transparente o processo de gestão dos recursos públicos, dando, portanto, à população melhores informações sobre como determinados investimentos e gastos de custeio afetam a economia de uma região e do país, permitindo inclusive avaliar seus governantes quanto às decisões tomadas.

É, portanto, a partir desse enfoque que se pretende fazer a avaliação econômica de impacto da Universidade de Brasília no Distrito Federal e no Brasil, calculando os impactos gerados tanto pelas atividades de investimento e de custeio da Universidade, como pela presença dos alunos, professores e servidores na cidade, em específico aqueles que passam a desenvolver suas atividades sociais e econômicas no Distrito Federal, atraídos pela presença da UnB.

Não se cogita entrar no mérito do acerto ou não dessa política de promoção da universidade pública no Brasil, nem da questão da relevância desta vis-à-vis outra política que o governo federal poderia implementar com os mesmos recursos. Pretende-se, sim, avaliar os principais impactos que podem ser caracterizados como resultados de uma ação característica de governo.

\section{Metodologia}

A Matriz Insumo Produto - $\mathrm{MIP}^{1}$ representa um arcabouço conciso para sintetizar e apresentar dados de uma economia, em um formato padronizado, conciliando fontes de informações distintas. Por meio dos dados desaa matriz, é possível verificar relações intersetoriais e inter-regionais, a partir de informações detalhadas referentes à demanda final das instituições, o valor adicionado das atividades, os impostos indiretos e o número de pessoas ocupadas por atividade.

O economista Leontief, precursor da análise de insumo-produto, conseguiu estruturar a "fotografia" da economia. Nesta fotografia, mostrou como os setores estão relacionados entre si, ou seja, quais setores suprem os outros de serviços e produtos, e quais setores compram de quais.

O resultado foi uma visão única e compreensivel de como a economia funciona e como cada setor é mais ou menos dependente um do outro. Esse sistema de interdependência é formalmente demonstrado em uma tabela conhecida como Matriz de Insumo-Produto (MIP).

\footnotetext{
${ }^{1}$ A matriz de insumo-produto foi implementada inicialmente por Leontief (1951).
} 
As estimações das MIPs demandam grandes esforços, já que requerem uma coleção de informações sobre cada setor da economia, a respeito dos seus fluxos de vendas e das suas fontes de insumos.

\subsection{Modelo de insumo-produto inter-regional}

O modelo de insumo-produto inter-regional adotado neste estudo capta os efeitos spillover e feedback entre as regiões (Miller e Blair, 1985). Qualquer elevação ou queda da produção em uma região, motivada por variação na demanda final, definida como sendo a soma do consumo das famílias, consumo do governo, exportações e investimento, afeta não apenas aquela região, mas todas as outras regiões que produzem os insumos que essa região utiliza.

Suponha, como exemplo, uma elevação na demanda final no Distrito Federal, seja por um aumento no consumo das famílias, no consumo do governo ou no investimento, público ou privado. Para atender a essa demanda, produtos devem ser fabricados e serviços prestados, não apenas no Distrito Federal, mas também nas demais unidades da federação que vendem produtos ao Distrito Federal. O efeito de aumento de produção nas demais regiões, por conta de um aumento de demanda no Distrito Federal, é denominado efeito spillover. Ainda, para possibilitar esse aumento de produção nos demais estados, é possível que as empresas demandem insumos ao longo de sua cadeia produtiva de empresas localizadas dentro ou fora do Distrito Federal. Assim, a produção no Distrito Federal e fora dele aumenta novamente, por um efeito de cadeias produtivas interligadas geograficamente entre os estados, sendo este denominado efeito feedback.

O modelo utilizado neste trabalho conta com duas regiões geográficas: o Distrito Federal (DF) e uma região que engloba as 26 outras unidades da federação brasileiras, denominada Resto do Brasil (RB). Foram considerados 149 setores de atividade para ambas as regiões.

A matriz $Z$, abaixo, representa os fluxos de consumo intermediário entre todos os setores, bem como entre as duas regiões, sendo uma matriz quadrada de dimensão $298 \times 298$.

$$
Z=\left[\begin{array}{cccccc}
Z_{1,1}^{D F, D F} & \cdots & Z_{1,149}^{D F, D F} & Z_{1,1}^{D F, R B} & \cdots & Z_{1,149}^{D F, R B} \\
\vdots & \ddots & \vdots & \vdots & \ddots & \vdots \\
Z_{149,1}^{D F, D F} & \cdots & Z_{149, D F}^{D F, D F} & Z_{14,1}^{D F, R B} & \cdots & Z_{149,149}^{D F, R B} \\
Z_{1,1}^{R B, D F} & \cdots & Z_{1,149}^{R B, D F} & Z_{1,1}^{R B, R B} & \cdots & Z_{1,149}^{R B, R B} \\
\vdots & \ddots & \vdots & \vdots & \ddots & \vdots \\
Z_{149,1}^{R B, D F} & \cdots & Z_{149,149}^{R B, D F} & Z_{149,1}^{R B, R B} & \cdots & Z_{149,149}^{R B, R B}
\end{array}\right]
$$

sendo cada elemento $Z_{i, j}^{s, r}$ e considerando que: 
$r=$ região de origem do produto, ou onde ele está sendo fabricado, que pode ser no DF ou no RB;

$s=$ região de destino do produto, ou onde ele está sendo incorporado no processo produtivo como produto intermediário, que pode ser no DF ou no RB;

$i=$ setor que está vendendo o produto intermediário;

$j$ = setor que está adquirindo o produto intermediário.

A matriz $Z$ também denominada de matriz de fluxos inter-regionais e setoriais de produtos intermediários deve ser calculada para que a análise de insumo-produto seja realizada. Adicionalmente, é necessário definir os vetores de produção, X, e de demanda final, Y.

O vetor de produção representa o valor produzido por cada setor, em cada região, e pode ser assim representado:

$$
X=\left[\begin{array}{c}
x_{1}^{D F} \\
\vdots \\
x_{149}^{D F} \\
x_{1}^{R B} \\
\vdots \\
x_{149}^{R B}
\end{array}\right]
$$

Sendo que cada elemento é $x_{i}^{r}$, ou seja, indexado à região e ao setor onde o produto foi fabricado.

A demanda final, Y, por sua vez, é composta pelo consumo das famílias, C, pelo investimento I, pelo Consumo do Governo, G, e pelas exportações, E. Sendo representada como:

$$
Y=C+I+G+E
$$

O vetor de demanda final representa todos os destinos dos bens finais produzidos em uma economia, em cada setor e em cada região. O vetor de demanda final pode ser representado da seguinte maneira: 


$$
Y=\left[\begin{array}{c}
y_{1}^{D F} \\
\vdots \\
y_{149}^{D F} \\
y_{1}^{R B} \\
\vdots \\
y_{149}^{R B}
\end{array}\right]=\left[\begin{array}{c}
c_{1}^{D F} \\
\vdots \\
c_{149}^{D F} \\
c_{1}^{R B} \\
\vdots \\
c_{149}^{R B}
\end{array}\right]+\left[\begin{array}{c}
i_{1}^{D F} \\
\vdots \\
i_{149}^{D F} \\
i_{1}^{R B} \\
\vdots \\
i_{149}^{R B}
\end{array}\right]+\left[\begin{array}{c}
g_{1}^{D F} \\
\vdots \\
g_{149}^{D F} \\
g_{1}^{R B} \\
\vdots \\
g_{149}^{R B}
\end{array}\right]+\left[\begin{array}{c}
e_{1}^{D F} \\
\vdots \\
e_{149}^{D F} \\
e_{1}^{R B} \\
\vdots \\
e_{149}^{R B}
\end{array}\right]
$$

Sendo que cada elemento $y_{i}^{s}$, é indexado ao setor i no qual o produto final foi produzido e à região R onde foi consumido pela família $\left(c_{i}^{R}\right)$ ou pelo governo $\left(g_{i}^{R}\right)$, foi investido $\left(i_{i}^{R}\right)$ ou foi exportado $\left(e_{i}^{R}\right)$.

A partir da matriz $Z$, é possivel elaborar uma matriz de coeficientes técnicos setoriais e regionais, denominada matriz $\mathrm{A}$, cujos elementos são calculados a partir dos elementos da matriz $Z$ e do vetor $X$ conforme o critério abaixo.

(i) Caso o coeficiente técnico represente o fluxo dentro de uma mesma região:

$$
a_{i j}^{r r}=\frac{z_{i j}^{r r}}{x_{j}^{r}}
$$

(ii) Caso o coeficiente técnico represente o fluxo entre regiões diferentes:

$$
a_{i j}^{s r}=\frac{z_{i j}^{s r}}{x_{j}^{r}}
$$

A matriz A pode, então, ser representada desta forma:

$$
A=\left[\begin{array}{cccccc}
a_{1,1}^{D F, D F} & \cdots & a_{1,149}^{D F, D F} & a_{1,1}^{D F, R B} & \cdots & a_{1,149}^{D F, R B} \\
\vdots & \ddots & \vdots & \vdots & \ddots & \vdots \\
a_{149, D}^{D F, D F} & \cdots & a_{149, D F}^{D F, D} & a_{149,1}^{D F, R B} & \cdots & a_{149,149}^{D F, R B} \\
a_{1,1}^{R B, D F} & \cdots & a_{1,149}^{R B, D F} & a_{1,1}^{R B, R B} & \cdots & a_{1,149}^{R B, R B} \\
\vdots & \ddots & \vdots & \vdots & \ddots & \vdots \\
a_{149,1}^{R B, D F} & \cdots & a_{149,149}^{R B, D F} & a_{149,1}^{R B, R B} & \cdots & a_{149,149}^{R B, R B}
\end{array}\right]
$$

A matriz A, portanto, apresenta os coeficientes técnicos de produção de cada setor em cada região.

Assim, quando se pré-multiplica um vetor de demanda final Y pela matriz A, obtémse a quantidade de insumos que precisa ser produzida nos 149 setores de cada região para que essa demanda final seja alcançada. Isso, no entanto, representa apenas uma iteração da cadeia produtiva. Por exemplo, para se produzir uma sobremesa no 
setor de alimentação fora do domicílio no Distrito Federal, é necessário comprar ovos da granja local, leite e manteiga da fazenda local e farinha de trigo e corante do resto do Brasil. No entanto, cada um desses itens tem uma cadeia produtiva própria, que precisa ser acionada para que esses bens estejam disponiveis para servirem como insumos na produção da sobremesa. $T_{1}=Y A$, sendo que $T_{1}$ é a produção necessária para se produzir os insumos para a produção, na primeira iteração. Logo, é necessário tornar $T_{1}$ uma nova demanda final e pré-multiplicar o vetor pela matriz A, gerando $T_{2}$. Isso deve ocorrer infinitamente, pois cada produto utilizado como insumo em cada etapa da cadeia produtiva tem sua cadeia produtiva própria. É importante notar que os valores são sucessivamente menores e que essa série infinita converge para um valor final finito.

Dessa forma, é possivel estabelecer uma relação entre a produção total e a demanda final a partir da matriz A, estando essa relação representada abaixo:

$$
X=A X+Y
$$

Rearranjando, chega-se à identidade de Leontief, em que é possivel estabelecer a produção final a partir da demanda final e dos coeficientes que caracterizam a estrutura produtiva:

$$
X=(I-A)^{-1} Y
$$

Tal que as variações no produto total serão expressas por:

$$
\Delta X=B \Delta Y
$$

em que $B=(I-A)^{-1}$.

Assim, é possivel determinar, ao longo de toda a cadeia produtiva, quanto é necessário produzir em cada setor e em cada região para atender a uma demanda final Y. Voltando ao exemplo, a equação acima determina tudo que foi produzido, no DF e no resto do Brasil, para se fabricar o bolo, inclusive a ração para as galinhas da granja no DF, a produção de soja para essas rações, a produção de fertilizantes para essa produção de soja e assim sucessivamente.

As simulações dos impactos econômicos da UnB foram realizadas por meio de um choque na demanda final considerado os quatros diferentes componentes, a saber: 1) consumo dos estudantes; 2) consumo dos servidores da Universidade custeados pela folha de pagamento da UnB; 3) itens de custeio da universidade; e 4) os investimentos da universidade. Os dois primeiros componentes compõem o consumo das famílias, o terceiro compõe o consumo do governo e o quarto, o investimento agregado 
da economia, sendo todos elementos da demanda final, como exposto acima.

\subsection{Uso de modelos de insumo-produto inter-regionais para estimar im- pacto de IFES}

Existem vários estudos usando matrizes de insumo-produto para analisar o potencial econômico de uma IFES em diferentes países. Felsentein (1996) avalia os impactos da Universidade de Northwestern sobre a região central de Chicago. Kelly, McLellan e McNicoll (2009) estudaram os efeitos das universidades sobre a economia do Reino Unido. Para o Brasil, podemos citar o trabalho de Rolim e Kureski (2010), que inicia a proposição de metodologia a ser seguida para a avaliação do impacto econômico de universidades no Brasil e, posteriormente, o trabalho de Vinhais (2013), que fez uma análise generalizada e regionalizada de impacto da expansão das universidades federais no Brasil, com base em dados do portal transparência do governo federal.

Os estudos se pautam na compreensão de como as estruturas econômicas e regionais têm de se adaptar para a prestação de serviços, em termos da movimentação econômica promovida pelas universidades, envolvendo além dos investimentos e custos para operação de uma universidade, as despesas realizadas pelos estudantes e pelos trabalhadores que se beneficiam dos recebimentos oriundos das suas atividades na universidade.

Todo recurso movimentado pela presença da universidade, seja do lado dos ofertantes quanto dos demandantes, implicará em impactos indiretos em outros setores, além dos impactos induzidos devido ao aumento da renda dos trabalhadores no setor em si, bem como em setores afetados de forma indireta. Esses impactos repercutem na ampliação do produto potencial das regiões, ou seja, na sua produção de bens e serviços ao longo do tempo.

Os impactos expressam-se por meio da injeção de gastos adicionais de investimentos quando for o caso, por exemplo em construção e/ou ampliação de infraestrutura e novas facilidades disponibilizadas, e os gastos com custeio e servidores, bem como as despesas dos estudantes.

Pelo lado da demanda, fez-se necessário realizar duas pesquisas de demanda, com intuito de mensurar e qualificar os hábitos de consumo dos alunos (estrangeiros, nacionais e da própria unidade da federação) e também dos servidores. Pelo lado da oferta do serviço de educação superior e demais atividades da universidade, faz-se necessária uma pesquisa em dados secundários de custeio e investimentos. Finalmente, os impactos puderam ser contabilizados em termos de maiores níveis de produção, valor adicionado bruto, massa salarial, emprego e arrecadação de impostos diretos e indiretos.

Os impactos de curto prazo, que intensificam o uso da capacidade produtiva e o uso dos fatores de produção disponíveis, geram os efeitos multiplicadores sobre as 
economias local, estadual e nacional. Os efeitos multiplicadores desses gastos se dão através dos efeitos de encadeamento para trás (a demanda de insumos) e dos efeitos induzidos pela demanda final dos trabalhadores afetados. Nesse processo de ativação das cadeias produtivas, em diferentes níveis do espaço econômico nacional, vão se criando novas oportunidades de emprego para diversos tipos de mão de obra, com maior ou menor nível de especialização, e ampliando a massa salarial.

Em consonância com estudos de análise de impactos na economia, com o uso da metodologia de matriz insumo-produto, os efeitos foram classificados em:

a. Diretos: incluem aquelas categorias econômicas diretamente afetadas pelas atividades mobilizadas pela variação no nível de consumo e investimento, podendo ser considerados os efeitos de substituição de consumo e de geração de nova demanda;

b. Indiretos: são os efeitos produzidos dentro da cadeia produtiva do setor, ou seja, dada uma expansão na demanda do setor, haverá um estímulo na produção de todos os insumos necessários à produção desse setor;

c. Induzidos: exprimem-se através das compras realizadas pelos consumidores, empregados direta e indiretamente, através das atividades econômicas beneficiadas pela variação dos investimentos e demais componentes da demanda final.

Para o cálculo dos efeitos considerados neste trabalho, consideramos as definições apresentadas a seguir.

A partir do sistema de Leontief $X=(I-A)^{-1} Y$, podemos mensurar o impacto que as mudanças ocorridas na demanda final $(Y)$, ou em cada um de seus componentes (consumo das famílias, gastos do governo, investimentos e exportações), teriam sobre a produção total $(X)$, o emprego $\left(V_{E}\right)$, os impostos indiretos líquidos $\left(V_{I}\right)$, as remunerações $\left(V_{R}\right)$ e o valor adicionado bruto $\left(V_{V A B}\right)$ Neste artigo, conforme listado anteriormente, consideramos os impactos sobre: consumo dos estudantes; consumo dos servidores da Universidade custeados pela folha de pagamento da UnB; itens de custeio da universidade e investimentos da universidade. Assim, cada impacto sobre a produção foi determinado a partir das Equações (4) e (5) a seguir:

$$
\begin{gathered}
\Delta X=(I-A)^{-1} \Delta Y \\
\Delta V=v \Delta X
\end{gathered}
$$

$\Delta V$ é um vetor com os 149 setores da economia nas duas regiões do modelo que representa o impacto sobre qualquer uma das variáveis, ou seja: emprego, impostos indiretos líquidos, remunerações e valor adicionado bruto. Observa-se que v é um vetor de coeficientes obtidos por meio da divisão, para cada um dos 149 setores da economia em cada uma das duas regiões, do valor correspondente a cada informação 
(emprego, remuneração, valor adicionado bruto e valor arrecadado) pelo respectivo valor da produção $(X)$ do setor.

$$
v_{i}^{R}=\frac{v_{i}^{R}}{x_{i}^{R}}
$$

A partir dos coeficientes estimados no modelo de Leontief, podemos também calcular os geradores direto, indireto e induzido de renda, emprego, valor adicionado bruto, impostos, entre outros, para cada setor da economia, ou seja, quanto é gerado, por exemplo, de emprego direta e indiretamente, para cada unidade monetária produzida para a demanda final Miller (2009). Esse indicador é estimado conforme a Equação (7).

$$
G V_{j}=\sum_{i=1}^{n} b_{i j} v_{i}
$$

$G V_{j}$ é o impacto total, direto e indireto, sobre a variável importação, ou qualquer outra variável em questão, como produção, salários, etc. $b_{i j}$ é o um elemento da matriz inversa de Leontief e $v_{i}$ é o coeficiente direto, definido conforme equação (6).

Além dos efeitos diretos e indiretos, pode-se também determinar os efeitos induzidos, que são decorrentes do fato de que os aumentos nos empregos e na renda estimulam o aumento da produção dos vários setores para atender ao consumo acrescido pelo ganho de massa salarial de trabalhos formais, informais e autônomos. Para se calcular o efeito induzido, é preciso tornar endógenos o consumo e a renda das famílias no modelo de insumo-produto; assim, em vez de utilizar a matriz A descrita acima, vamos ter:

$$
\bar{A}=\left[\begin{array}{cc}
A & H_{c} \\
H_{r} & 0
\end{array}\right]
$$

$\bar{A}$ é a nova matriz de coeficientes técnicos de ordem $(n+1) \mathbf{x}(n+1)$ contendo a renda (Hr) e o consumo $(H c)$ das famílias. Na renda das famílias, não foi considerado o Rendimento Misto Bruto, que incluiria o lucro das famílias com suas participações em pessoas jurídicas. Da mesma forma, os novos vetores de produção total $\bar{X}_{(n+1) \times 1}$ e de demanda final $\bar{Y}_{(n+1) \times 1}$ vão ser representados, respectivamente, por:

$$
\begin{aligned}
& \bar{X}=\left[\begin{array}{c}
X \\
X_{n+1}
\end{array}\right] \\
& \bar{Y}=\left[\begin{array}{c}
Y^{*} \\
Y_{n+1}^{*}
\end{array}\right]
\end{aligned}
$$

Em que os novos componentes estão relacionados à endogeneização do consumo e da renda das famílias.

Logo, o sistema de Leontief definido na Equação (2) seria representado como: 


$$
\begin{gathered}
\Delta \bar{Y}=\bar{B} \Delta \bar{X} \\
\bar{B}=(I-\bar{A})^{-1}
\end{gathered}
$$

A distribuição espacial desses efeitos multiplicadores, ou seja, a sua distribuição entre as economias das regiões e do país, irá depender de vários fatores estruturais, locacionais e culturais. De modo geral, pode-se afirmar que deve ser grande a probabilidade de que os efeitos multiplicadores sejam mais intensos nas suas respectivas economias (municípios ou estados) e nas regiões mais desenvolvidas, que dispõem de uma estrutura produtiva ampla do ponto de vista setorial e com relações intersetoriais mais integradas.

A importância deste estudo pode ser observada de um lado pela preocupação em avaliar os impactos econômicos associados à presença da UnB no DF em diferentes níveis espaciais (regional e nacional) e do outro pela preocupação em avaliar o grau de mobilização setorial ocorrido em cada um desses níveis, visando captar o seu grau de ativação social.

\section{Análise dos dados}

\subsection{Resultados dos questionários}

Como parte deste estudo, foram desenvolvidas pesquisas diretas com alunos e servidores da UnB. Nesta seção, são apresentadas estatísticas descritivas da amostra e das variáveis pesquisadas para os dois públicos ${ }^{2}$.

\subsubsection{Pesquisa direta com alunos da UnB}

Para identificar o volume da variação da demanda final, relativa ao consumo das famílias, representada pelo consumo dos estudantes no DF, realizou-se pesquisa direta para identificação do padrão de consumo dos estudantes.

Neste estudo, considerou-se que os alunos vindos de outras Unidades da Federação para cursar a UnB gerariam redução de consumo das famílias no restante do Brasil. No entanto, o padrão de consumo no DF foi pautado com base em pesquisa direta com amostra de 1.203 estudantes. A Hipótese de trabalho é que sem a UnB os estudantes vindos de fora não iriam para o DF e que os estudantes já residentes no DF antes de entrar na UnB iriam buscar ensino em outras regiões. Os autores compreendem que esta é uma hipótese forte, mas qualquer configuração diferente também seria hipotética, uma vez que é impossivel saber qual a proporção de alunos que sairia do DF para buscar a graduação em outras regiões e quantos alunos de fora buscariam o

\footnotetext{
${ }^{2} \mathrm{O}$ questionário completo pode ser visualizado no link: https://drive.google.com/file/d/1SrPOayfj YT16bDCPgO37jnB5Bhob927q/view?usp=sharing
} 
DF para se graduar, mesmo sem a existência da UnB. Essa definição sobre o choque de demanda final derivada do consumo dos alunos exige esse tipo de hipótese uma vez que, mesmo se fossem questionados, muitos alunos não seriam capazes de afirmar onde estariam se não existisse a UnB.

A pesquisa direta com os alunos da UnB atingiu uma amostra de $1.203^{3}$, dos quais 315 são alunos que vieram ao DF para cursar a UnB e 888 já residiam no DF. Os alunos da amostra provenientes de outras unidades da federação são, em sua maioria, provenientes de Goiás. Em seguida, aparecem os estados de Minas Gerais e São Paulo, conforme Figura 1.

Figura 1. Distribuição da amostra conforme região de origem do aluno da UnB

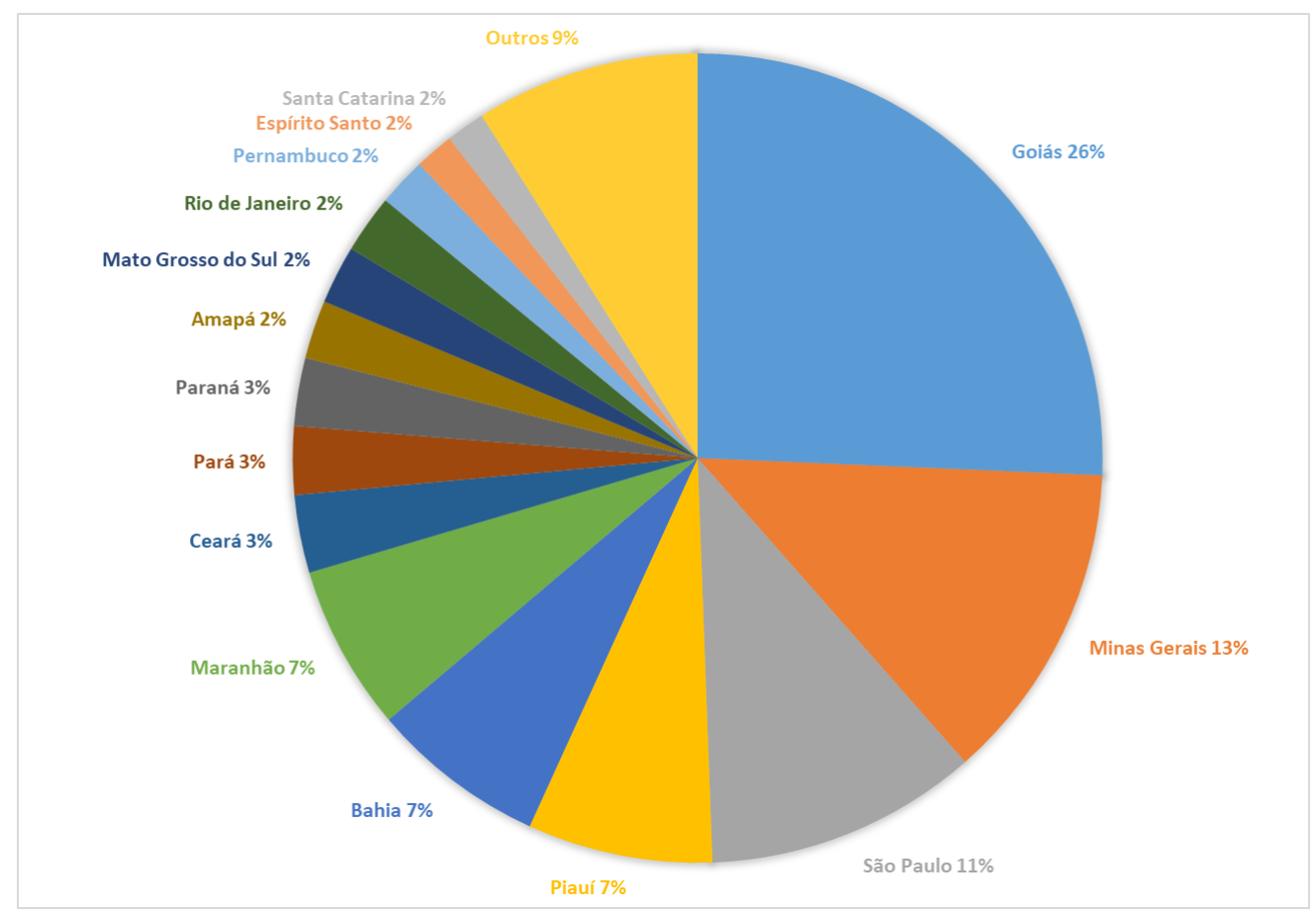

Fonte: Elaboração própria, com base nos dados primários da pesquisa.

A amostra atingiu alunos de 71 cursos, distribuídos conforme o Figura 2. A amostra tem como característica uma boa dispersão e representatividade dos cursos da universidade, não estando concentrada em algum curso ou área específica.

Dos 1.203 alunos que participaram da amostra, 1.200 são alunos de cursos presenciais e apenas 3 de cursos da modalidade EaD. A idade média dos alunos que compõem a amostra é de 26 anos, distribuídos pelas faixas etárias, conforme o Figura 3.

O padrão de gastos dos alunos foi pesquisado como subsídio para definição dos gastos diretos desee público. Os valores foram tabulados para dois grupos de alunos,

\footnotetext{
${ }^{3} \mathrm{~A}$ amostra já considera o número de questionários completos e com respostas válidas em todas as questões.
} 
Figura 2. Distribuição da amostra entre os cursos da UnB

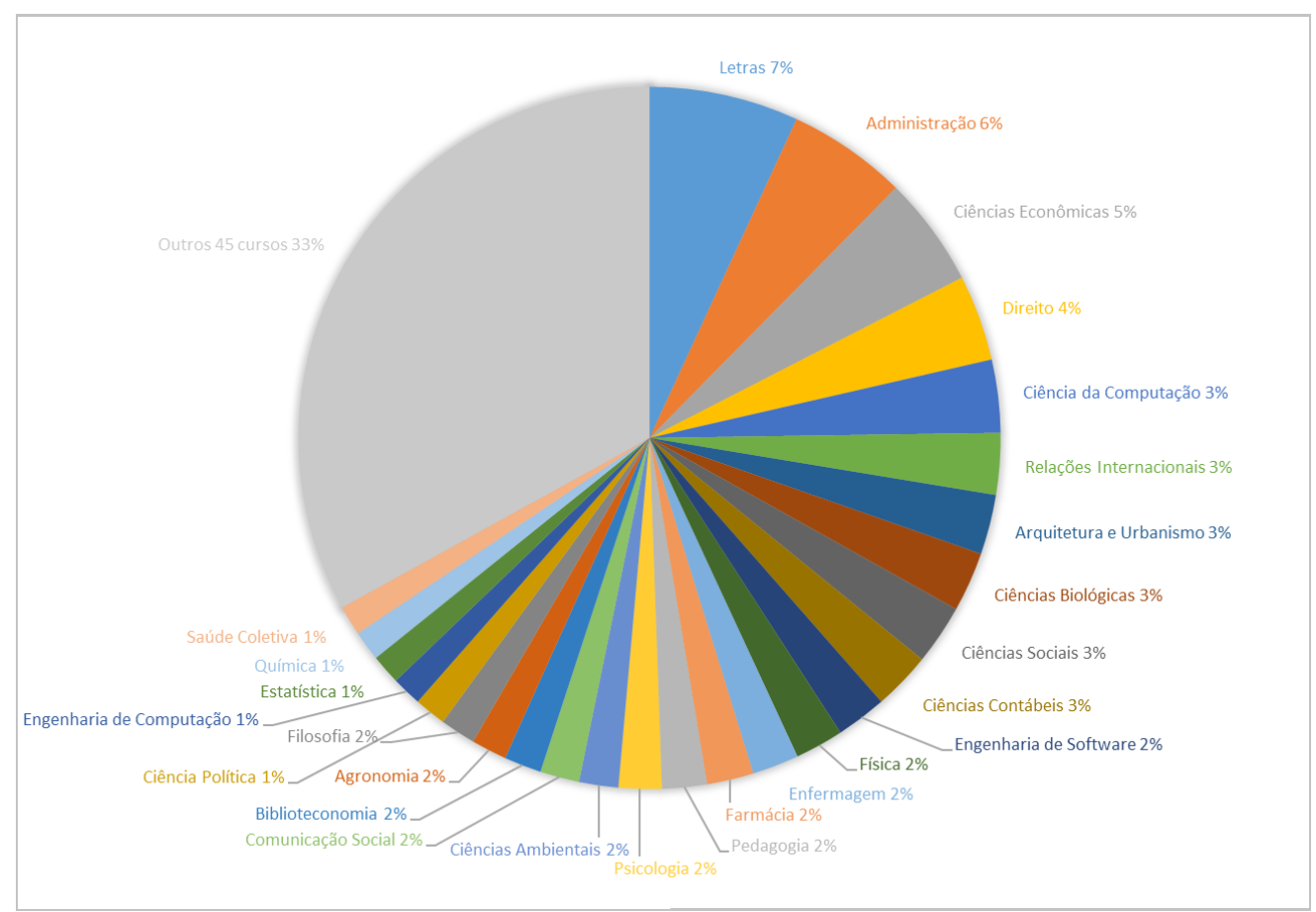

Fonte: Elaboração própria, com base nos dados primários da pesquisa.

Figura 3. Faixa etária dos alunos que compõem a amostra da pesquisa direta

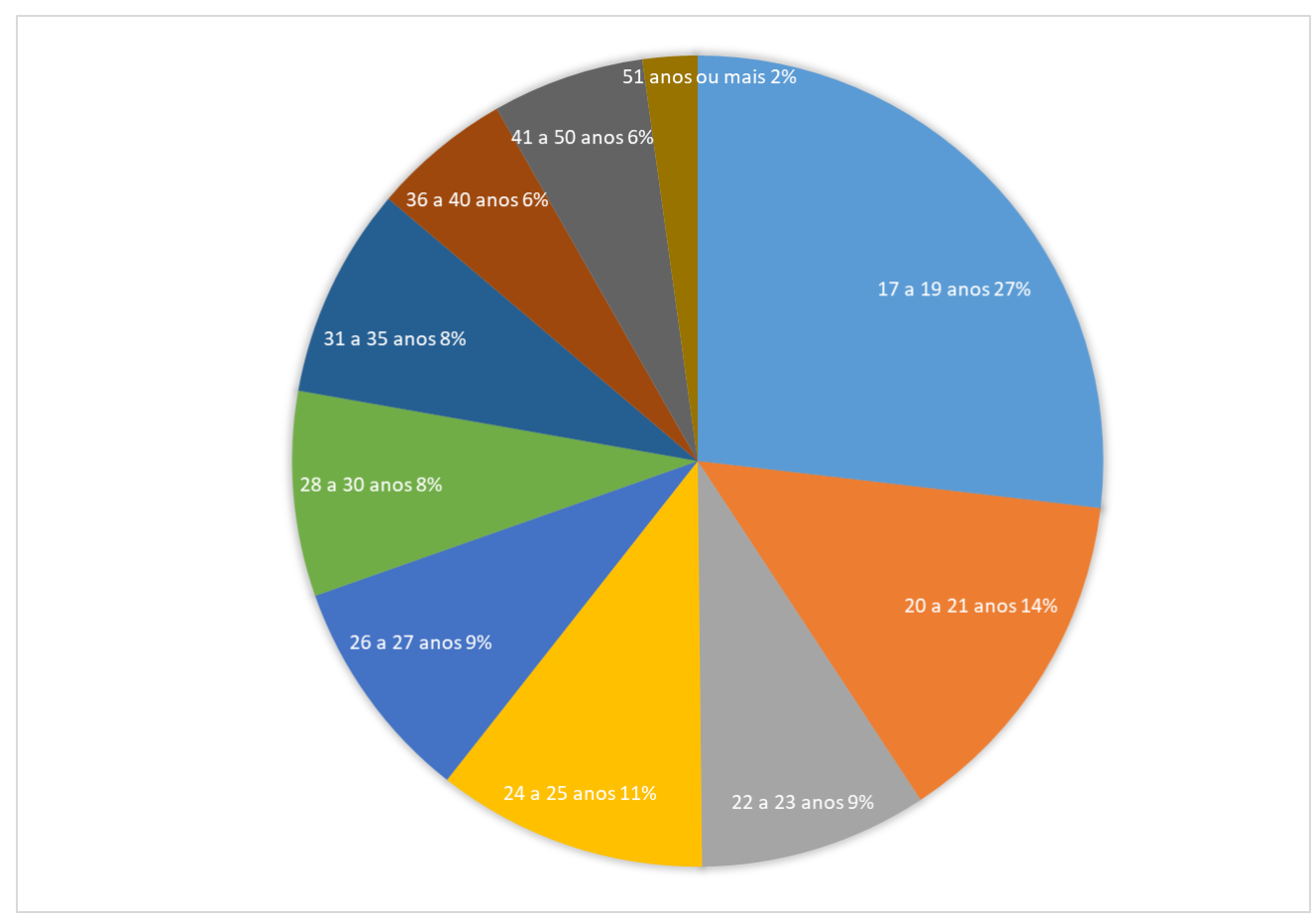

Fonte: Elaboração própria, com base nos dados primários da pesquisa.

os que já residiam no DF e os que vieram de fora para cursar a UnB. Tal discriminação é justificada não apenas pelo padrão de gastos bastante heterogêneo, mas também com o intuito de permitir que os resultados dos impactos fossem apresentados em 
separado para esses dois grupos. Os gastos médios de cada grupo foram expandidos pelo total de alunos de cada tipo de origem, conforme dados de registros acadêmicos da quantidade de alunos provenientes de outras UFs. Além disso, o gasto realizado no DF por alunos que vieram de outras UFs foi descontado do consumo das famílias nas suas regiões de origem (RB). Garantiu-se assim que não houvesse dupla contagem de gastos na economia brasileira. As Figuras 4 e 5 exibem esses padrões de gastos.

Figura 4. Gastos mensais médios dos alunos oriundos do DF

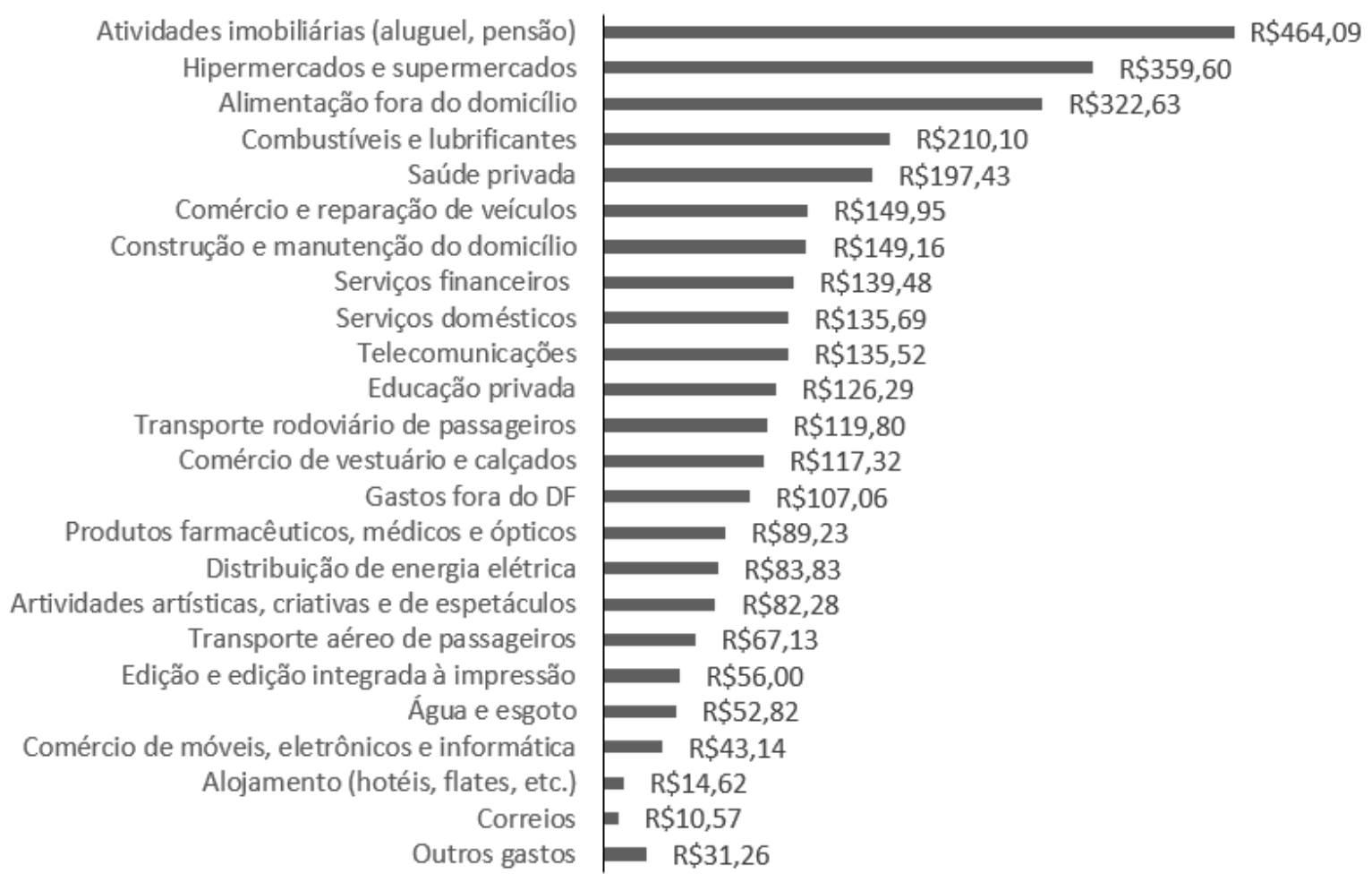

Fonte: Elaboração própria, com base nos dados primários da pesquisa.

\subsubsection{Pesquisa direta com colaboradores da UnB}

A pesquisa direta realizada com os colaboradores da UnB teve como principal objetivo identificar os padrões de consumo daqueles que têm renda oriunda de pagamentos da universidade. Com os dados da pesquisa, foi possivel direcionar os impactos diretos nos setores e nas regiões da economia em que os gastos dos servidores são realizados como elo inicial de ativação da economia.

A amostra da pesquisa atingiu um total de 395 colaboradores, sendo a maioria servidores,376, mas também abrangendo funcionários terceirizados, em contratos temporários e aposentados.

A Figura 6 apresenta a composição dos gastos dos colaboradores da UnB, em termos de proporções da totalidade de seus gastos. Esses valores foram estimados com base na pesquisa direta e, posteriormente, foram usados como parâmetros nas esti- 
Figura 5. Gastos mensais médios dos alunos que vieram de outras unidades da federação

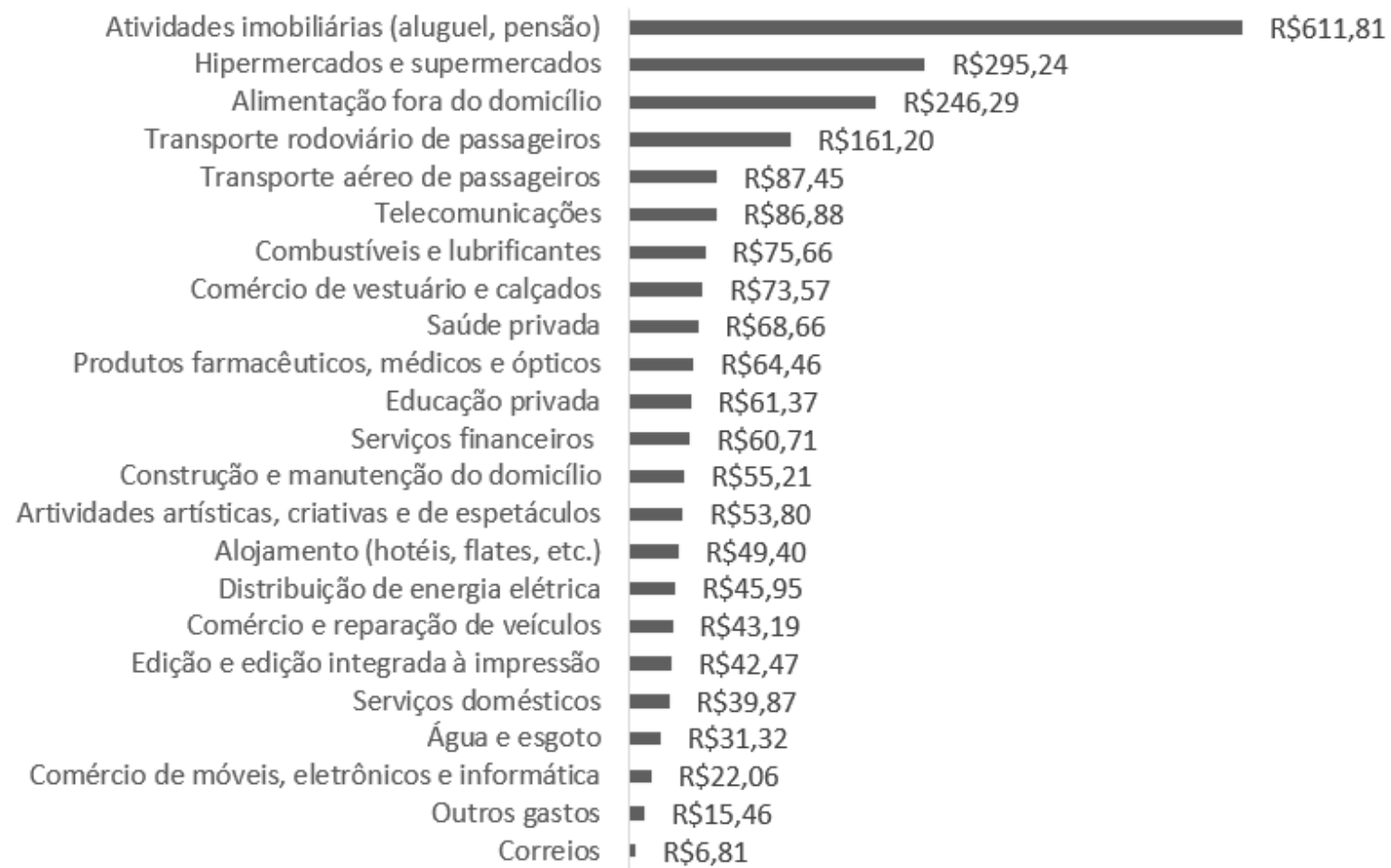

Fonte: Elaboração própria, com base nos dados primários da pesquisa.

mativas de choque direto da totalidade de gastos junto com as informações de massa salarial da UnB, extraídas do portal de transparência do Governo Federal.

\subsection{Análise dos resultados das simulações}

Incialmente, foi estimada, pelo professor Joaquim Guilhoto, a MIP inter-regional para o DF, contendo 149 setores e duas regiões, o Distrito Federal e as demais regiões do país. Essa matriz foi estimada com os coeficientes técnicos de produção para o ano de 2011 e seguiu a metodologia definida em Ichihara et al. (2013) e Guilhoto et al. (2019). A estimação de uma MIP dessa complexidade utiliza diversas fontes de informações tais como: Censo-IBGE, PNAD-IBGE, PAS-IBGE, PIA-IBGE, PAM-IBGE, PPM-IBGE, PAC-IBGE, PEVS-IBGE, RAIS-MTE, ISS, ICMS, dentre outras, e um complexo sistema computacional para elaboração da matriz regionalizada.

Após a obtenção da MIP inter-regional para o DF, o passo seguinte para alcançar os objetivos propostos foi realizar pesquisa direta com alunos e servidores, conforme apresentado no item anterior. As simulações foram realizadas de forma separada, isto é, foram consideradas as estruturas de consumo dos alunos da UnB, tanto os residem no DF quanto aqueles que vieram de outras regiões do Brasil, consumos dos servidores (ativos e aposentados) e terceirizados da UnB e investimento realizado pela 
Figura 6. Composição dos gastos dos servidores UnB - Estimativa pesquisa Direta

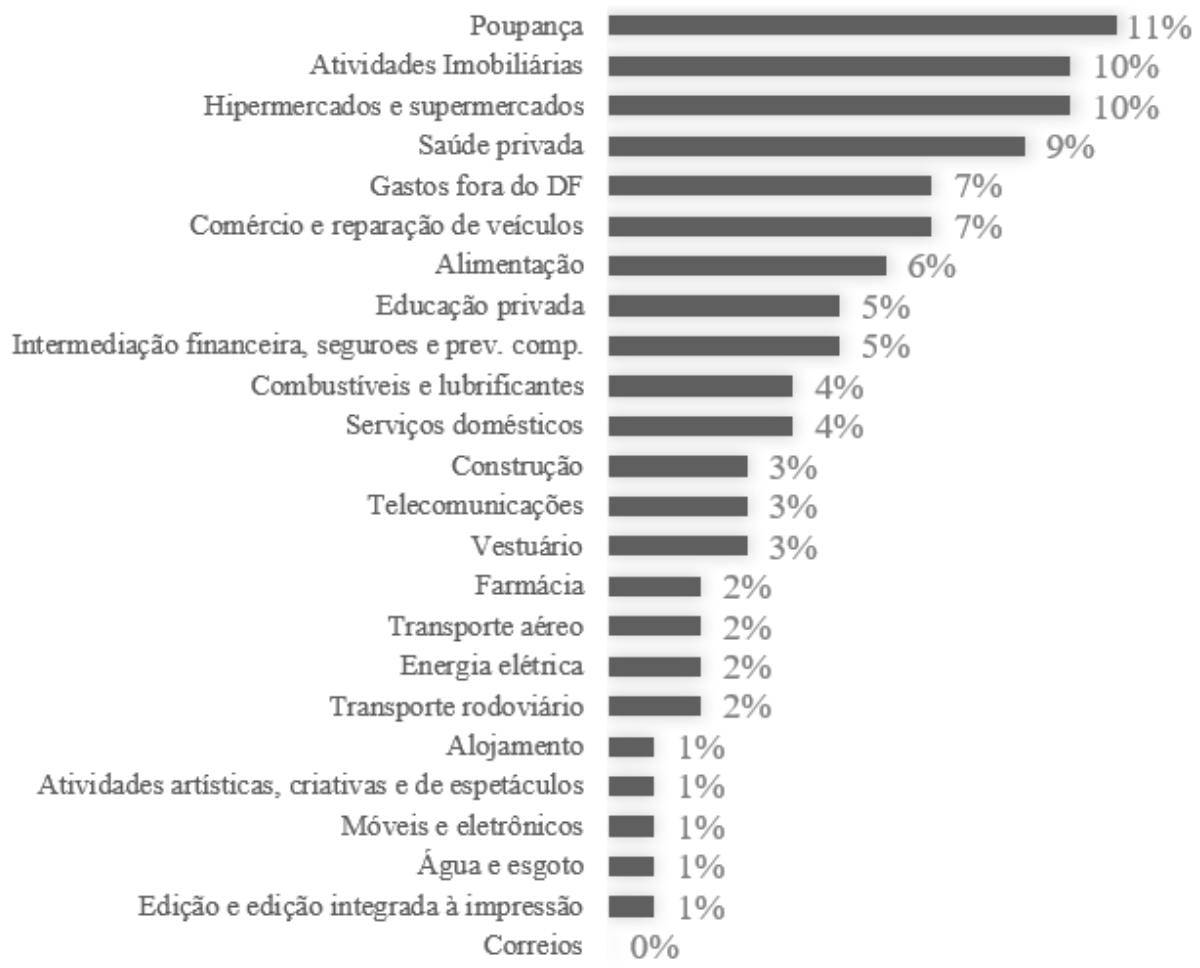

Fonte: Elaboração própria, com base nos dados primários da pesquisa.

UnB no ano de $2019^{4}$.

Os indicadores que permitiram avaliar os impactos da UnB na economia do DF foram: Valor Bruto da Produção - VBP, Valor Adicionado Bruto - VAB, Empregos e Impostos Indiretos. Impostos Indiretos são as arrecadações de ICMS, IPI, Impostos de Importação, ISS, entre outros, conforme divulgados pelo IBGE, nas Tabelas de Recursos e Usos.

O gasto médio dos alunos que estudam na UnB e já residiam no DF foi identificado na pesquisa, descrita no item 4.1.1, como sendo igual a $\mathrm{R} \$ 3.265$ e dos estudantes que vieram de outras regiões como sendo igual a $\mathrm{R} \$ 2.299$.

Os valores desses gastos médios dos alunos provenientes de outras regiões fora do DF e residentes foram expandidos pelo total de alunos da universidade, conforme números apresentados na Tabela 1, e posteriormente definidos como choques diretos.

Os valores de gastos tiveram os descontos de margens de transporte e de comércio sendo realocados nesses setores. O consumo em supermercados e hipermercados, por sua vez, foi distribuído entre os setores da economia, conforme o padrão de consumo obtido da Pesquisa de Orçamentos Familiares do IBGE de 2009 para os residentes no DF.

\footnotetext{
${ }^{4}$ Os valores da MIP foram atualizados de 2011 para 2019, com o uso do IPCA-IBGE.
} 
Tabela 1. Universo de Alunos da UnB para expansão dos gastos médios.

\begin{tabular}{lcccc}
\hline \hline & & \multicolumn{2}{c}{ Brasil } & \\
\cline { 3 - 4 } & Exterior & & & Total \\
Vinculo & & DF & Outras UFs & \\
\hline Graduação & 341 & 30.324 & 12.843 & 43.508 \\
Pós-Graduação & 351 & 3.686 & 5.627 & 9.664 \\
Total de alunos & $\mathbf{6 9 2}$ & $\mathbf{3 4 . 0 1 0}$ & $\mathbf{1 8 . 4 7 0}$ & $\mathbf{5 3 . 1 7 2}$ \\
\hline \hline
\end{tabular}

Fonte: Elaboração própria, com base em dados da Reitoria da UnB.

Após realizada a pesquisa sobre o consumo dos servidores e terceirizados da UnB, conforme descrito na seção 5.2.1, foi estimada a composição dos padrões de gastos dos colaboradores da UnB e aplicaram-se as proporções na totalidade dos vencimentos disponíveis para consumo, ou seja, reduzido dos impostos e poupança. Para identificar a totalidade dos recebimentos dos colaboradores da UnB, foram utilizados dados disponiveis no portal da transparência do governo federal do Brasil.

Para avaliar o impacto econômico das despesas correntes e dos investimentos, o Decanato de Planejamento e Orçamento forneceu dados da execução do orçamento, de 2018. Os dados foram categorizados conforme a relação da natureza detalhada da despesa com os setores da economia considerados na matriz de insumo-produto utilizada e a localização da empresa beneficiada. As despesas com gastos correntes (custeio) e investimento totalizaram R\$ 232 milhões em 2018. Adicionalmente, considerou-se como demais gastos da universidade as obrigações patronais, que totalizam mais R $\$ 190$ milhões.

\subsection{Resultados dos impactos econômicos}

Uma vez estimado o vetor variação na demanda final, considerando os segmentos estudantes, servidores e investimentos, foi possivel calcular os impactos diretos, indiretos e induzidos sobre o Valor Bruto da Produção, Produto Interno Bruto (medido a valor adicionado bruto, ou seja, diferença entre o Valor Bruto da Produção e Consumo Intermediário), número de empregos e arrecadação de impostos indiretos líquidos. Esses valores foram calculados para o DF e também para o Resto do Brasil.

Além da importância social da universidade, como formadora de cidadãos altamente capacitados, a UnB é responsável por 44.998 empregos no DF, o que equivale a 3,7\% das pessoas ocupadas na unidade da federação. Nesse sentido, vale ressaltar que a taxa de desemprego no DF passaria dos atuais 12,5\% (conforme dados do quarto trimestre de 2019 da PNAD-C do IBGE) para 16,2\%, sem a UnB. 
A Tabela 2 mostra que os setores que mais geram empregos com a presença da UnB são os de serviços domésticos, outros serviços e alimentação. Os resultados podem ser analisados de forma discriminada entre os gerados pelos alunos, servidores e da estrutura universitária de custeio e investimentos. Nota-se que a movimentação econômica promovida pelos alunos é a que mais gera empregos, seguida da movimentação dos servidores e funcionários.

Tabela 2. Impactos totais (diretos + indiretos + induzidos) setoriais e regionais da UnB no DF - Número de Empregos

\begin{tabular}{lcccc}
\hline \hline Setores & Alunos & $\begin{array}{c}\text { Servidores/ } \\
\text { Funcionários }\end{array}$ & $\begin{array}{c}\text { Custeio e } \\
\text { investimentos }\end{array}$ & Total \\
\hline Extrativa mineral & 1 & 1 & 0 & 2 \\
S.I.U.P & 81 & 45 & 26 & 152 \\
Comércio atacadista & 179 & 126 & 31 & 336 \\
Bens de consumo duráveis & 90 & 344 & 11 & 445 \\
Atividades imobiliárias & 296 & 137 & 19 & 452 \\
Serviços públicos & 26 & 17 & 615 & 657 \\
Indústria alimentícia & 676 & 393 & 14 & 1.083 \\
Supermercados & 671 & 404 & 44 & 1.119 \\
Transporte & 1.090 & 213 & 71 & 1.374 \\
Atividades artísticas e de espetáculos & 1.063 & 405 & 45 & 1.513 \\
Saúde privada & 753 & 818 & 26 & 1.597 \\
Agropecuária & 1.140 & 670 & 18 & 1.828 \\
Educação privada & 1.154 & 1.002 & 68 & 2.225 \\
Outras indústrias & 1.746 & 1.305 & 204 & 3.255 \\
Outros Comércios varejistas & 3.362 & 1.910 & 362 & 5.635 \\
Alimentação & 3.726 & 1.698 & 453 & 5.876 \\
Outros serviços & 2.873 & 1.569 & 1.765 & 6.206 \\
Serviços domésticos & 6.120 & 4.912 & 211 & 11.243 \\
TOTAL & $\mathbf{2 5 . 0 4 7}$ & $\mathbf{1 5 . 9 6 7}$ & $\mathbf{3 . 9 8 4}$ & $\mathbf{4 4 . 9 9 8}$ \\
\hline \hline
\end{tabular}

Fonte: Elaboração própria. 
Quando se analisa o Valor Bruto da Produção, tem-se que a presença da UnB no DF movimentou em 2019 a soma de R\$ 4,2 bilhões. Conforme os resultados apresentados na Tabela 3, pode-se notar que outros serviços e atividades imobiliárias são os setores mais afetados. Sendo novamente os estudantes os responsáveis pela maior movimentação de recursos.

Tabela 3. Impactos totais (diretos + indiretos + induzidos) setoriais da UnB no DF Valor Bruto da Produção em reais

\begin{tabular}{lcccc}
\hline \hline Setores & Alunos & $\begin{array}{c}\text { Servidores/ } \\
\text { Funcionários }\end{array}$ & $\begin{array}{c}\text { Custeio e } \\
\text { investimentos }\end{array}$ & Total \\
\hline Extrativa mineral & 56.307 & 114.378 & 3.810 & 174.495 \\
Atividades artísticas e & 43.399 .177 & 16.552 .747 & 1.858 .207 & 61.810 .131 \\
de espetáculos & & & & \\
Supermercados & 43.883 .721 & 26.393 .000 & 2.906 .615 & 73.183 .336 \\
Comércio atacadista & 40.033 .523 & 26.881 .861 & 6.421 .313 & 73.336 .697 \\
Agropecuária & 54.863 .832 & 32.294 .871 & 1.075 .178 & 88.233 .881 \\
Bens de consumo duráveis & 29.251 .696 & 80.897 .217 & 3.009 .937 & 113.158 .849 \\
Serviços domésticos & 71.941 .028 & 57.736 .251 & 2.480 .689 & 132.157 .968 \\
Educação privada & 76.486 .043 & 66.426 .994 & 4.510 .579 & 147.423 .615 \\
S.I.U.P. & 85.231 .160 & 45.503 .416 & 20.780 .225 & 151.514 .800 \\
Outros Comércios varejistas & 107.035 .579 & 61.489 .209 & 12.465 .964 & 180.990 .752 \\
Indústria Alimentícia & 125.837 .254 & 72.893 .908 & 2.953 .473 & 201.684 .635 \\
Serviços Públicos & 8.126 .674 & 5.184 .562 & 201.711 .249 & 215.022 .485 \\
Saúde Privada & 114.285 .260 & 124.077 .603 & 3.908 .261 & 242.271 .124 \\
Transporte & 177.620 .372 & 57.439 .074 & 13.319 .824 & 248.379 .270 \\
Alimentação & 195.451 .092 & 89.045 .550 & 23.735 .933 & 308.232 .575 \\
Outras Indústrias & 200.492 .196 & 144.546 .984 & 18.932 .851 & 363.972 .031 \\
Atividades Imobiliárias & 392.895 .449 & 181.138 .481 & 25.150 .098 & 599.184 .028 \\
Outros Serviços & 484.751 .943 & 286.439 .929 & 222.177 .848 & 993.369 .720 \\
TotAL & $\mathbf{2 . 2 5 1 . 6 4 2 . 3 0 7}$ & $\mathbf{1 . 3 7 5 . 0 5 6 . 0 3 3}$ & $\mathbf{5 6 7 . 4 0 2 . 0 5 2}$ & $\mathbf{4 . 1 9 4 . 1 0 0 . 3 9 2}$ \\
\hline \hline & & & & \\
& & & & \\
\hline
\end{tabular}

Fonte: Elaboração própria. 
De toda a renda gerada no DF, medida pelo PIB, mais de $\mathrm{R} \$ 2,4$ bilhões estão associados ao VAB da UnB, ou seja, o impacto total equivale à cerca de 1,0\% do PIB do DF. Esses valores estão apresentados na Tabela 4 e indicam como setores mais beneficiados os de outros serviços, atividades imobiliárias, alimentação e saúde privada. Se somados os valores dos IIL, atinge-se $1,1 \%$ do PIB.

Tabela 4. Impactos totais (diretos + indiretos + induzidos) setoriais da UnB no DF Valor Adicionado Bruto em reais

\begin{tabular}{|c|c|c|c|c|}
\hline Setores & Alunos & $\begin{array}{l}\text { Servidores/ } \\
\text { Funcionários }\end{array}$ & $\begin{array}{c}\text { Custeio e } \\
\text { investimentos }\end{array}$ & Total \\
\hline Extrativa mineral & 41.165 & 68.915 & 2244,378916 & 112.324 \\
\hline $\begin{array}{l}\text { Atividades artísticas e } \\
\text { de espetáculos }\end{array}$ & 21.913 .080 & 8.357 .800 & 938244,5333 & 31.209 .124 \\
\hline Bens de consumo duráveis & 8.879 .434 & 33.966 .897 & 997780,6799 & 43.844 .111 \\
\hline Agropecuária & 29.794 .372 & 17.540 .292 & 606061,024 & 47.940 .725 \\
\hline Comércio atacadista & 26.665 .326 & 17.905 .503 & 4327042,123 & 48.796 .871 \\
\hline Supermercados & 30.578 .679 & 18.390 .945 & 2025362,549 & 50.994 .986 \\
\hline S.I.U.P. & 32.186 .602 & 17.206 .574 & 7926483,189 & 57.319 .660 \\
\hline Indústria alimentícia & 35.773 .015 & 20.595 .576 & 1031692,147 & 57.400 .283 \\
\hline Educação privada & 51.530 .445 & 44.753 .427 & 3038883,178 & 99.322 .756 \\
\hline Transporte & 80.730 .705 & 21.342 .547 & 5890129,705 & 107.963.382 \\
\hline Serviços públicos & 4.371 .545 & 2.785 .449 & 107746648,2 & 114.903 .643 \\
\hline Outras indústrias & 64.645 .227 & 52.778 .440 & 9166879,819 & 126.590 .547 \\
\hline Serviços domésticos & 71.941 .028 & 57.736 .251 & 2480688,609 & 132.157.968 \\
\hline Outros comércios varejistas & 79.503 .081 & 45.682 .785 & 9195372,09 & 134.381 .238 \\
\hline Saúde privada & 65.071 .137 & 70.646 .649 & 2225264,853 & 137.943 .051 \\
\hline Alimentação & 108.892 .910 & 49.610 .514 & 13224151,44 & 171.727 .575 \\
\hline Atividades imobiliárias & 357.656 .293 & 164.892 .003 & 22894362,11 & 545.442 .658 \\
\hline Outros serviços & 278.083 .675 & 166.401 .486 & 128493881,8 & 572.979 .043 \\
\hline TOTAL & 1.348.257.719 & 810.561 .053 & 322.211 .172 & 2.481 .029 .944 \\
\hline
\end{tabular}

Fonte: Elaboração própria. 
Na Tabela 5, por sua vez, são apresentados os efeitos da sobre a arrecadação de impostos indiretos líquidos (IIL) no DF, motivados pela movimentação econômica gerada a partir da UnB. Destacam-se como principais arrecadadores os setores de outros serviços, outras indústrias e transportes. A arrecadação tributária total de IIL no DF somou R\$ 277 milhões.

Tabela 5. Impactos totais (diretos + indiretos + induzidos) setoriais da UnB no DF Arrecadação de Impostos Indiretos Líquidos

\begin{tabular}{|c|c|c|c|c|}
\hline Setores & Alunos & $\begin{array}{c}\text { Servidores/ } \\
\text { Funcionários }\end{array}$ & $\begin{array}{c}\text { Custeio e } \\
\text { investimentos }\end{array}$ & Total \\
\hline Serviços domésticos & 0 & 0 & 0 & 0 \\
\hline Extrativa mineral & 3.024 & 9.883 & 333 & 13.239 \\
\hline Comércio atacadista & 1.475 .136 & 996.466 & 228292 & 2.699 .894 \\
\hline Supermercados & 1.658 .447 & 997.440 & 109846 & 2.765 .734 \\
\hline Atividades artísticas & 2.742 .069 & 1.045 .844 & 117406 & 3.905 .319 \\
\hline Agropecuária & 3.920 .172 & 2.306 .606 & 70453 & 6.297 .231 \\
\hline Educação privada & 3.306 .675 & 2.871 .798 & 195003 & 6.373 .475 \\
\hline Outros Comércios varejistas & 3.849 .822 & 2.199 .054 & 447002 & 6.495 .878 \\
\hline Atividades imobiliárias & 5.335 .053 & 2.459 .645 & 341508 & 8.136 .207 \\
\hline Serviços públicos & 451.355 & 290.486 & 10935240 & 11.678 .081 \\
\hline S.I.U.P. & 7.234 .131 & 3.864 .978 & 1773856 & 12.872 .965 \\
\hline Bens de consumo duráveis & 4.408 .303 & 8.494 .141 & 475580 & 13.378 .025 \\
\hline Indústria alimentícia & 8.531 .144 & 4.928 .674 & 218182 & 13.678 .000 \\
\hline Saúde privada & 8.172 .808 & 8.873 .082 & 279489 & 17.325 .379 \\
\hline Alimentação & 16.974 .554 & 7.733 .436 & 2061420 & 26.769 .411 \\
\hline Transporte & 24.449 .132 & 10.327 .539 & 1728421 & 36.505 .092 \\
\hline Outras indústrias & 30.020 .667 & 18.765.993 & 1518221 & 50.304 .881 \\
\hline Outros serviços & 29.195 .828 & 16.898.205 & 11654092 & 57.748 .125 \\
\hline TOTAL & 151.728.321 & 93.063 .270 & 32.155.347 & 276.946.937 \\
\hline
\end{tabular}

Fonte: Elaboração própria. 
Os impactos totais no Brasil estão na Tabela 6, na qual pode-se observar que o transbordamento do consumo e dos investimentos associados à existência da UnB no DF é positivo nas demais regiões do Brasil.

Tabela 6. Impacto econômico da Universidade de Brasília, considerando os efeitos diretos, indiretos e induzidos

\begin{tabular}{lrrr}
\hline \hline Setores & DF & Outras UFs & Total \\
\hline Valor Bruto da Produção & & & \\
(R\$ bilhões) & 4,2 & 1,3 & 5,5 \\
Valor adicionado Bruto & & & \\
(R\$ bilhões) & 2,5 & 0,5 & 3 \\
Empregos & & & \\
(número) & 44.998 & 7.691 & 52.690 \\
Arrecadação de impostos indiretos & & & \\
(R\$ milhões) & 276,9 & 68,5 & 345,4 \\
\hline \hline
\end{tabular}

Fonte: Elaboração própria.

\section{Conclusões}

O estudo permitiu mensurar os impactos econômicos que a Universidade de Brasília exerce na economia do DF, a partir dos seus choques diretos na demanda final da economia brasileira e com o uso de instrumental de Matriz de Insumo Produto interregional. Uma vez identificada a estrutura de consumo dos servidores, terceirizados e estudantes da UnB, assim como os investimentos e as despesas de custeio foi possivel realizar estimações por meio do modelo de Leontief e avaliar os impactos sobre o Valor Bruto Produção-VBP, Valor Adicionado Bruto-VAB, Empregos e arrecadação de Impostos Indiretos Líquidos.

O consumo dos estudantes da UnB gera um impacto total (direto + indireto + induzido) de mais R $\$ 2,3$ bilhões no VBP do DF. Destaca-se a participação do Setor Imobiliário, com cerca de R\$393 milhões e o setor de Alimentação com R\$195 milhões. A geração de empregos devido à movimentação da economia pelos estudantes foi da ordem de 25.047 empregos, ou seja, 1,8\% das ocupações da cidade. O impacto em termos de VAB do DF foi de R $\$ 1,4$ bilhões, isso equivale a 0,6\% do PIB do DF. $\mathrm{O}$ acréscimo de arrecadação de impostos indiretos líquidos no DF foi de mais de R $\$ 150$ milhões com a presença dos alunos da UnB.

O consumo dos Servidores e Terceirizados, ativos e aposentados, também foi estimado pela pesquisa direta. Esse consumo produz um impacto de R $\$ 1,4$ bilhão no VBP do DF, sendo que o setor imobiliário obteve um valor de $\mathrm{R} \$ 181,1$ milhões e o setor 
de Saúde Privada recebeu R\$124 milhões. Os efeitos sobre os empregos no DF são de 15.967 novos empregos na cidade, não contabilizando os empregos dos próprios funcionários, o que representa cerca de $1,1 \%$ das ocupações do DF. O impacto em termos de VAB foi de R\$810 milhões, o que equivale a 0,3\% do PIB do DF.

Os resultados do estudo permitem afirmar que a Universidade de Brasília, além da importância social como formadora de cidadãos com altas qualificações, também tem um papel importante na economia, seja pelo total de empregos da ordem de 52.260 no DF, o que equivale a 3,7\% das pessoas ocupadas na unidade da federação, ressaltando que a taxa de desemprego no DF passaria dos atuais 12,5\% para 16,2\% sem a UnB, ou ainda, pelo valor movimentado em todos os setores do DF que somou cerca de $\mathrm{R} \$$ 4,2 bilhões no Valor Bruto da Produção.

De toda a renda gerada no $\mathrm{DF}$, mais de $\mathrm{R} \$ 2,4$ bilhões estão associados à UnB. Ou seja, 1,0\% do PIB do DF, que acrescido da arrecadação de IIL, atinge 1,1\% do PIB.

Quando avaliamos os impactos na economia brasileira, chega-se a uma geração de 52.690 empregos e um acréscimo de 3,0 bilhões no PIB, já considerando os descontos de redução de consumo na região de origem dos estudantes. Desse total de renda gerada, quase R\$ 2,5 bilhões são para os moradores do DF. Os demais estados do Brasil também são beneficiados com um acréscimo de $\mathrm{R} \$ 484$ milhões em termos de PIB e cerca de 7,7 mil empregos.

Destaca-se ainda que os autores não consideram os impactos econômicos de uma universidade como estritamente esses associados à sua movimentação econômica e sua cadeia de valor. Os impactos econômicos do ponto de vista social estão muito mais associados aos ganhos de produtividade que o ensino superior de qualidade promove, beneficiando seus ex-alunos com melhores salários e melhores padrões de vida.

\section{Referências}

Felsenstein, D. (1996). The university in the metropolitan arena: impacts and public policy implications. Urban studies, 33(9):1565-1580.

Guilhoto, J. J. M., Junior, C. A. G., Visentin, J. C., Imori, D., e Ussami, K. A. (2019). Sistema interestadual de insumo-produto do Brasil: uma aplicação do método SUIT. Economia Aplicada, 23(1):83-112.

Ichihara, S. M., Guilhoto, J. J. M., e Imori, D. (2013). Regional development and government income transfer programs: Combining input-output systems and geoprocessing as tools for planning in São Paulo State, Brazil. In: Geography, Institutions and Regional Economic Performance, Página 415-436. Springer, New York.

Kelly, U.; Mclellan, D. e Mcnicoll, I. (2009). The impact of University on the UK Economy. Texto para discussão, London: Universities UK. 
Kureski, R. e Rolim, C. (2010). Impacto econômico de curto prazo das universidades federais na economia brasileira. Artigo apresentado no XIII Encontro Regional de Economia. Porto Alegre-RS. Agosto 11-13.

Leontief, W. W. (1951). The structure of American economy, 1919-1939: an empirical application of equilibrium analysis. Oxford University Press, New York.

Miller, R.E.; Blair, P. (2009). Input-Output Analysis: Foundations and Extensions, volume 2. Cambridge University Press, Cambrige.

Miller, R. e Blair, P. (1985). Input-Output Analysis: Foundations and Extensions. Prentice-Hall, Englewood Cliffs.

Niquito, T. W., Ribeiro, F. G., e Portugal, M. S. (2018). Impacto da criação das novas universidades federais sobre as economias locais. Planejamento e Políticas Públicas, (51).

Vinhais, H. E. F. (2013). Estudo sobre o impacto da expansão das universidades federais no Brasil. Tese de Doutorado, Universidade de São Paulo.

Este artigo está licenciado com uma CC BY 4.0 license. 